\title{
ASUHAN KEPERAWATAN KETIDAKNYAMANAN PASCA PARTUM DI RUANGAN DAHLIA RUMAH SAKIT UMUM DAERAH LIUN KENDAGE TAHUNA
}

\author{
NURSING CARE OF INCONVENIENCES OF POST PARTUM IN DAHLIA WARD \\ PUBLIC HOSPITAL LIUNKENDAGE TAHUNA
}

\author{
Amelia Banualawo, Yeanneke Liesbeth Tinungki, Christien Angreni Rambi \\ Program Studi Keperawatan Politeknik Negeri Nusa Utara \\ Email: yeanneketinungki82@gmail.com
}

\begin{abstract}
Abstrak: Persalinan dapat menyebabkan luka di daerah perineum sehingga akan menyebabkan ketidaknyamanan pasca partum berupa nyeri pada luka jahitan perineum. Ketidaknyamanan pasca partum merupakan perasaan tidak nyaman yang berhubungan dengan kondisi setelah melahirkan. Tujuan penelitian adalah menerapkan asuhan keperawatan ketidaknyamanan pasca partum di ruangan Dahlia Rumah Sakit Daerah Liun Kendage Tahuna. Metode penelitian adalah studi kasus dengan pendekatan proses keperawatan, dengan subyek penelitian yaitu dua ibu pasca partum. Hasil penelitian ini dilakukan dengan menerapkan proses keperawatan.

Tindakan keperawatan yang dilakukan yaitu mengidentifikasi nyeri pada ibu, mengontrol lingkungan yang memperberat rasa nyeri, membatasi pengunjung yang datang, mengajarkan teknik nonfarmakologis yaitu teknik relaksasi napas dalam, monitor tanda-tanda vital, mengajarkan kepada ibu untuk beraktivitas yang ringan seperti berjalan disekitar ruangan dan duduk dan menganjurkan kepada ibu agar perineum tetap bersih dan sesering mungkin mengganti pembalut. Kesimpulan penelitian ini menunjukkan bahwa perasaan nyaman yang berhubungan dengan kondisi setelah melahirkan meningkat. Saran diharapkan ibu nifas dapat mempertahankan kebersihan perineum pada saat masa nifas sehingga penyembuhan luka perineum ibu dapat berjalan dengan normal dan merasakan kenyamanan pasca partum.
\end{abstract}

Kata Kunci: Ketidaknyamanan, pasca partum

\begin{abstract}
Childbirth can cause injury in the perineal area so that it will cause post-partum discomfort in the form of pain in the perineal suture wound. Post partum discomfort is the feeling of discomfort associated with the postpartum condition. The research objective was to apply Postpartum Discomfort Nursing Care in the Dahlia room Public Hospital Liun Kendage Tahuna. The research method was a case study with a nursing process approach, with the research subject, namely two post-partum mothers. The result of this study were conducted by applying the nursing process. Nursing actions taken are identifying pain in the mother, controlling the environment that aggravates the pain, limiting visitors who come, teaching non-pharmacological techniques, namely deep breathing relaxation techniques, monitoring vital signs, teaching mothers to do light activities such as walking around the room and sat down and advised the mother to keep the perineum clean and to change the pads as often as possible. The conclusion of this study shows that the feeling of comfort associated with postpartum conditions increases. Suggestion It is hoped that postpartum mothers can maintain perineal cleanliness during the puerperium so that the healing of the mother's perineal wounds can run normally and feel comfortable after partum.
\end{abstract}

Keyword: Inconveniences, Post Partum 


\section{PENDAHULUAN}

Persalinan dapat menyebabkan luka di daerah perineum sehingga akan menyebabkan ketidaknyamanan pasca partum berupa nyeri pada luka jahitan perineum. Ketidaknyamanan pasca partum merupakan perasaan tidak nyaman yang berhubungan dengan kondisi setelah melahirkan (Suryandari, 2019). Kementerian Kesehatan 2018 menunjukan adanya tingkat kesehatan ibu di Indonesia yang membaik dibandingkan pada 2013 salah satu indikatornya ialah meningkatnya proporsi pemeriksaan kehamilan dri 95,2\% menjadi 96,1\%. Peningkatan lain juga terlihat pada proporsi pelayanan kunjungan nifas lengkap yang meningkat dari 32,1\% menjadi 37\% (Riskesdas, 2018).

Ketidaknyamanan yang dirasakan oleh ibu pasca partum adalah nyeri yang dialami ibu nifas yang dijahit perineum sebelum dan setelah mendapatkan intervensi. 38\% ibu mengatakan nyeri perineum meningkat pada hari ketujuh setelah persalinan, $60 \%$ dari ibu primipara mengalami robekan perineum derajat 2 dan $91 \%$ mengalami robekan pada derajat 3 dan 4 . Terdapat 241 ibu postpartum mengalami nyeri perineum, 173 (92\%) ibu postpartum melaporkan nyeri perineum pada hari pertama (Rosmiyati, 2016).

Data yang penulis dapatkan di RSD Liun Kendage Tahuna pada bulan Januari sampai Desember 2019 ibu yang melahirkan berjumlah 121 orang dan pada bulan Januari sampai Februari 2020 sebanyak 47 orang baik persalinan normal maupun operasi (Rekam Medik RSD Liun Kendage Tahuna, 2020).

Proses yang terjadi setelah persalinan membuat seorang ibu merasa ketidaknyamanan pada dirinya terutama yang dirasakan baik itu melalui persalinan normal maupun dengan section caesarea.
Berdasarkan latar belakang di atas maka penulis tertarik untuk melakukan penelitian lebih lanjut mengenai asuhan keperawatan ketidaknyamanan pasca partum di ruangan Dahlia RSD Liun Kendage Tahuna.

\section{METODE PENELITIAN}

Penelitian ini menggunakan rancangan studi dengan pendekatan proses keperawatan. Tujuan penelitian adalah menerapkan asuhan keperawatan ketidaknyamanan pasca partum di ruangan Dahlia RSD Liun Kendage Tahuna. Subyek studi kasus yaitu dua orang klien di ruangan Dahlia dengan kriteria inklusi: 1) Ibu pasca partum normal; 2) Bersedia menjadi responden. Fokus studi kasus adalah asuhan keperawatan ketidaknyamanan nyeri pasca partum. Instrumen penelitian menggunakan format pengkajian maternitas dan nyeri. Studi kasus ini dilaksanakan tanggal 10-11 Maret 2020 di ruangan Dahlia RSD Liunkendage Tahuna. Pengumpulan data melalui lembar status kesehatan klien dan wawancara yang dilakukan. Penyajian data studi kasus ini disajikan dalam bentuk tabel dan narasi.

\section{HASIL DAN PEMBAHASAN}

Hasil Pengkajian didapatkan 2 Klien. Klien pertama Ny. D.M berusia 18 tahun, Perempuan beragama Kristen, Pekerjaan IRT, Pendidikan terakhir SD. Klien kedua berinisial Ny. K.L berusia 27 tahun, Perempuan beragama Kristen, pekerjaan Swasta, pendidikan terakhir S1.

Klien pertama memiliki keluhan utama yakni nyeri pada luka perineum ketika waktu kencing dan bergerak nyeri seperti ditusuk tusuk skala nyeri 7 . Riwayat kesehatan sekarang Klien mengatakan nyerinya hilang timbul seperti diiris-iris dan klien bisa bergerak dan masih merasa nyeri skala nyeri 7 
.Riwayat kehamilan G 2 P $1 \quad$ A0.TD : Pemeriksaan Fisik TTV; 120/70 mmHg, R 24x/menit, N: 78 x/menit, $\mathrm{S}: 36,4{ }^{\circ} \mathrm{C}$. Pengkajian Nyeri PQRST; Q. nyeri yang dirasakan seperti diiris-iris, R. Nyeri dirasakan di daerah perineum, $\mathbf{S}$. Skala nyeri 7.T. 2-3 menit. Pemeriksaan abdomen ada striae, tidak ada masa pada abdomen, TFU: $\pm 2 \mathrm{~cm}$ di bawah umbilicus. Pemeriksaan dada mamae simetris, dan membengkak, aerola hiper pigmentasi, nipple menonjol, ekspansi paru simetris. Pemeriksaan perineum keluar darah sedikit $\pm 45 \mathrm{cc}$, luka episiotomy masih basah, kemerahan, tidak ada oedema, ada bintik kebiruan, tidak ada nanah, tidak ada perdarahan, jenis jahitan jelujur, jumlah jahitan dalam 4 dan luar 6. Tanda REEDA: Rednees (kemerahan): tidak ada kemerahan, Edema (bengkak): tidak ada bengkak, Echimosis : tidak ada drainage (rembesan): tidak terdapat rembesan, Approximately: tidak ada. Pemeriksaan vulva: Terdapat luka perineum $10 \mathrm{~cm}$ di daerah perineum karena episiotomy yang tertutup dengan kassa steril.

Klien kedua memiliki keluhan utama yakni nyeri pada luka perineum ketika waktu kencing dan bergerak nyeri seperti ditusuk tusuk skala nyeri 6 . Riwayat kesehatan sekarang klien mengatakan nyerinya hilang timbul seperti ditusuk-tusuk dan bisa bergerak dan masih merasa nyeri skala nyeri 6 . Riwayat kehamilan G1 P1 A0. Pemeriksaan TTV; TD : 110/80 mmHg, R : 22x/menit, N: 76 x/menit, S : $36{ }^{0} \mathrm{C}$. Pemeriksaan Nyeri PQRST. Q. nyeri yang dirasakan seperti tusuk-tusuk R. Nyeri dirasakan di daerah perineum. S. Skala nyeri 6. T. 2-5 menit. Pemeriksaan abdomen ada striae sedikit, tidak ada masa pada abdomen, TFU: $\pm 2 \mathrm{~cm}$ dibawah umbilicus. Pemeriksaan dada, mamae simetris, dan membengkak dan kemerahan, aerola hiper pigmentasi, nipple menonjol, ekspansi paru simetris.
Pemeriksaan perineum keluar darah sedikit \pm 40cc, luka episiotomy masih basah, kemerahan, tidak ada oedema, ada bintik kebiruan, tidak ada nanah, tidak ada perdarahan, jenis jahitan jelujur, jumlah jahitan dalam dan luar tidak dikaji. Tanda REEDA: Rednees (kemerahan): tidak ada kemerahan, Edema (bengkak): tidak ada bengkak, Echimosis : Tidak ada. Drainage (rembesan): tidak terdapat rembesan, Approximately: tidak ada. Pemeriksaan vulva: terdapat luka perineum $12 \mathrm{~cm}$ didaerah perineum karena episiotomy yang tertutup dengan kassa steril.

$$
\text { Diagnosis Keperawatan adalah }
$$

Ketidaknyamanan Pasca Partum berhubungan dengan trauma perineum selama persalinan dan kelahiran DS : Klien mengeluh tidak nyaman, DO : Ekspresi wajah meringis, terdapat kontraksi uterus, ada luka episiotomi dan payudara membengkak.

Standar Luaran Definisi: Perasaan nyaman yang berhubungan dengan kondisi setelah melahirkan Ekspetasi: Meningkat. Kriteria hasil : 1) Keluhan tidak nyaman (1), 2) Luka episiotomy (2), 3) Kontraksi uterus (2), 4) Berkeringat (1), 5) Menangis $(1), 6)$ Merintih (1), 7) Hemoroid (1), 8) Kontraksi uterus (1), 9) Payudara membengkak (1).

Intervensi Keperawatan

1. Manajemen Nyeri

a. Identifikasi lokasi, karakteristik, durasi, frekwensi, kualitas, intensitas nyeri

b. Identifikasi skala nyeri

c. Identifikasi respon nyeri non verbal

d. Identifikasi faktor yang memperberat dan memperingan nyeri

e. Identifikasi pengetahuan dan keyakinan tentang nyeri

f. Identifikasi pengaruh budaya terhadap respon nyeri 
g. Identifikasi pengaruh nyeri pada kualitas hidup

h. Monitor keberhasilan terapi komplementer yang sudah diberikan

i. Monitor efek samping penggunaan analgetik.

2. Terapeutik

a. Berikan teknik non famakologi untuk mengurangi rasa nyeri ( hypnosis, teknik imajinasi terbimbing, aromaterapi, terapi pijat, kompres hangat/dingin, terapi bermain)

b. Kontrol lingkungan yang memperberat rasa nyeri (mis. Suhu ruangan, pencahayaan, kebisingan

c. Fasilitas istirahat dan tidur

d. Pertimbangkan jenis dan sumber nyeri dalam pemilihan strategi meredakan nyeri.

3. Edukasi

a. Jelaskan penyebab, periode dan pemicu nyeri

b. Jelaskan strategi meredakan nyeri

c. Anjurkan memonitor nyeri secara mandiri

d. Anjurkan menggunakan analgetik secara tepat

e. Ajarkan teknik non farmakologi untuk mengurangi rasa nyeri.

4. Kolaborasi

Kolaborasi pemberian analgetik, jika perlu.

\section{IMPLEMENTASI}

Implementasi Klien 1 Hari pertama

Jam. 13.20 wita
1. Mengidentifikasi nyeri pada ibu (lokasi, karakteristik, durasi, frekuensi, intensitas nyeri)

Hasil: lokasi nyeri didaerah perineum, nyeri seperti diiris-iris, dirasakan hilang timbul selam 2-3 menit, skala nyeri 7

Jam 14.00 wita

2. Mengidentifikasi respon non verbal Hasil: wajah ibu meringis saat nyeri Jam 15.00 wita

3. Mengontrol lingkungan yang memperberat rasa nyeri (suhu, pencahayaan, kebisingan)

Hasil: Klien dapat beristirahat dengan lingkungan yang tenang.

4. Membatasi pengunjung yang datang Jam 15.00 wita

5. Mengajarkan teknik nonfarmakologis yaitu teknik relaksasi napas dalam.

Hasil: Ibu mengikuti teknik relaksasi nafas dalam yaitu tarik nafas dari hidung tahan selam 3-5 detik kemudian hembuskan perlahan-lahan melalui mulut.

Jam 18.00 wita

6. Monitor tanda-tanda vital

Hasil:TD. $\quad 110 / 70 \quad \mathrm{mmHg}, \quad$ N.97x/m, R. $24 x / m, S B .36^{\circ} \mathrm{c}$

Jam. 18.40 wita

7. Mengajarkan kepada ibu untuk berkativitas yang ringan seperti berjalan disekitar ruangan dan duduk

8. Mengajarkan kepada ibu tentang perawatan perineum

Jam 20.00 wita

9. Memberikan edukasi kepada ibu tentang penggunaan alat kontasepsi

Hasil: ibu memilih alat kontasepsi suntik 
Evaluasi hari I Jam 22.00 wita

$\mathrm{S}:$ Klien mengeluh tidak nyaman

O : Skala nyeri 5 (sedang), aktivitas klien terbatas, ekspresi wajah meringis. Terdapat kontraksi uterus, ada luka episiotomy dan payudara membengkak

A : Masalah belum teratasi

P : Lanjutkan intervensi

Implementasi Klien 2 hari pertama

Jam 10.00 wita

1. Mengidentifikasi lokasi, karakteristik, frekuensi, intensitas nyeri

Hasil: lokasi nyeri didaerah perineum, nyeri seperti ditusuk-tusuk, selama 2-5 menit, skala nyeri 6

Jam 11.25 wita

2. Mengidentifikasi respon non verbal

Hasil: wajah ibu meringis saat nyeri 13.45 wita

3. Mengontrol lingkungan yang memperberat rasa nyeri (suhu, pencahayaan, kebisingan)

Hasil: Klien dapat beristirahat dengan lingkungan yang tenang.

4. Membatasi pengunjung yang datang Jam 15.00 wita

5. Mengajarkan teknik nonfarmakologis yaitu teknik relaksasi napas dalam.

Hasil: Ibu mengikuti teknik relaksasi nafas dalam yaitu tarik nafas dari hidung tahan selam 3-5 detik kemudian hembuskan perlahan-lahan melalui mulut.

Jam

Jam 16.30 wita

6. Monitor tanda-tanda vital

Hasil: TD. 110/80 mmHg, N.86x/m, R. $24 \mathrm{x} / \mathrm{m}, \mathrm{SB} .36^{\circ} \mathrm{c}$

Jam 17.00 wita
7. Mengajarkan kepada ibu untuk berkativitas yang ringan seperti berjalan disekitar ruangan dan duduk

17.15 wita

8. Mengajarkan kepada ibu tentang perawatan perineum

Jam 20.15 wita

9. Memberikan edukasi kepada ibu tentang penggunaan alat kontasepsi

Hasil: ibu memilih alat kontasepsi pil

Jam 21.30 wita

$\mathrm{S}:$ Klien mengeluh tidak nyaman

O : Skala nyeri 4 (sedang), ekspresi wajah meringis, ekspresi wajah meringis. Terdapat kontraksi uterus, ada luka episiotomy dan payudara membengkak.

A : Masalah belum teratasi

P : Lanjutkan intervensi

Implementasi Klien 1 hari Kedua Jam 08.30 wita

1. Mengidentifikasi nyeri pada ibu (lokasi, karakteristik, durasi, frekuensi, intensitas nyeri)

Hasil: lokasi nyeri didaerah perineum, nyeri seperti diiris-iris, dirasakan hilang timbul selama 2-3 detik, skala nyeri 2 (ringan)

Jam 10.00 wita

2. Mengontrol lingkungan yang memperberat rasa nyeri (suhu, pencahayaan, kebisingan)

Hasil: Klien dapat beristirahat dengan lingkungan yang tenang.

Jam 11.20 wita

3. Membatasi pengunjung yang datang Jam 11.40 wita

4. Mengajarkan teknik nonfarmakologis yaitu teknik relaksasi napas dalam. 
Hasil: Ibu mengikuti teknik relaksasi nafas dalam yaitu tarik nafas dari hidung tahan selam 3-5 detik kemudian hembuskan perlahan-lahan melalui mulut.

Jam 13.00 wita

5. Monitor tanda-tanda vital

Hasil:TD. $\quad 110 / 70 \quad \mathrm{mmHg}, \quad \mathrm{N} .97 \mathrm{x} / \mathrm{m}$, R. $24 x / m, S B .36^{\circ} \mathrm{c}$

6. Mengajarkan kepada ibu untuk berkativitas yang ringan seperti berjalan disekitar ruangan dan duduk

Jam 13.15 wita

7. Menganjurkan kepada ibu agar perineum tetap bersih dan sesering mungkin mengganti pembalut.

14.00 wita

Menganjurkan kepada ibu untuk rutin minum ubat sesuai dengan dosis yang diberikan.

Evaluasi Jam 15.00 wita

$\mathrm{S}$ : Klien mengatakan nyeri berkurang

O : Skala nyeri 2 (ringan), klien tampak rileks, TD. 110/70 mmHg, N. 82x/m, R. 24x/m, SB. 36 ${ }^{\circ} \mathrm{c}$

A : Masalah teratasi

P : Klien diperbolehkan pulang oleh dokter. Intervensi dihentikan .

Implementasi Klien 2 Hari kedua

Jam 08.40 wita

1. Karakteristik, frekuensi, intensitas nyeri

Hasil: lokasi nyeri didaerah perineum, nyeri seperti ditusuk-tusuk, selama 2-3 detik, skala nyeri 2 (ringan)

Jam 09.15 wita

2. Mengontrol lingkungan yang memperberat rasa nyeri (suhu, pencahayaan, kebisingan)
Hasil: Klien dapat beristirahat dengan lingkungan yang tenang.

Jam 11.20 wita

3. Membatasi pengunjung yang datang Jam 11.45 wita

4. Mengajarkan teknik nonfarmakologis yaitu teknik relaksasi napas dalam.

Hasil: Ibu mengikuti teknik relaksasi nafas dalam yaitu tarik nafas dari hidung tahan selam 3-5 detik kemudian hembuskan perlahan-lahan melalui mulut.

Jam 12.45 wita

5. Monitor tanda-tanda vital

Hasil: TD. $110 / 80 \mathrm{mmHg}, \quad \mathrm{N} .86 \mathrm{x} / \mathrm{m}$, R. $24 \mathrm{x} / \mathrm{m}, \mathrm{SB} .36,2{ }^{\circ} \mathrm{c}$

6. Mengajarkan kepada ibu untuk berkativitas yang ringan seperti berjalan disekitar ruangan dan duduk

Jam 13.10 wita

7. Menganjurkan kepada ibu agar perineum tetap bersih dan sesering mungkin mengganti pembalut.

Jam 14.00 wita

Menganjurkan kepada ibu untuk rutin minum obat sesuai dengan dosis yang diberikan.

Jam 14.20 wita

$\mathrm{S}$ : Klien mengatakan nyeri berkurang

$\mathrm{O}$ : Skala nyeri 2 (ringan), klien tampak rileks. TD. 110/80 mmHg, N. 78x/m, R. 24x/m, SB. 36, 5॰c

A : Masalah teratasi

P : Klien diperbolehkan pulang oleh dokter. Intervensi dihentikan.

Berdasarkan pengkajian yang dilakukan selama dua hari keluhan utama pada kedua klien yaitu Ny. D.M mengatakan nyeri pada luka perineum ketika waktu kencing dan bergerak nyeri seperti di tusuk tusuk skala nyeri 7. Sedangkan pada Ny. K.L 
nyeri dirasakan pada luka perineum sama dengan yang dirasakan Ny. D.M yaitu saat berkemih dengan skala nyeri 6. Pemeriksaan tanda-tanda vital Ny. D.M TD : 120/70 mmHg, R 24x/menit, N: 78 x/menit, SB: $36,4^{\circ} \mathrm{C}$ dan Ny. K.L TD: $110 / 80 \mathrm{mmHg}$, R: 22x/menit, N: 76 x/menit, SB: $36{ }^{\circ} \mathrm{C}$. Luka perineum yang dialami oleh kedua ibu disebebkan karena tindakan episitomi saat persalinan normal.

Menurut Dewi (2018) episiotomi merupakan terputusnya kontinuitas jaringan sehingga menekan pembuluh saraf sekitar dan menyebabkan nyeri.Nyeri ádalah suatu keadaan dimana individu mengalami dan melaporkan adanya rasa tidak nyaman yang berat atau sensasi tidak nyaman, berakhir dari 1 detik sampai kurang dari 6 bulan. Luka perineum akan menyebabkan nyeri dan rasa tidak nyaman pada ibu postpartum, hal ini akan mengganggu interaksi ibu dan bayi, membuat ibu lebih rentan terkena infeksi dan terjadi perdarahan jika luka perineum tidak dipantau dengan baik (Rosmiyati, 2016).

Intervensi yang dilakukan pada kedua klien dapat mengurangi nyeri pada klien yaitu menganjurkan untuk beraktivitas seperti berjalan di sekitar ruangan, duduk dan bergerak melakukan aktivitas ringan. Menurut Mutmainna (2017) dalam penelitiannya dengan judul Manajemen Asuhan Kebidanan Pada Ibu Post Partum menyebutkan mobilisasi dini secara perlahan ibu akan mampu beradaptasi dengan nyeri yang dirasakannya dan akan membantu proses penyembuhan luka dengan cepat. Selain itu untuk mengurangi nyeri dapat menggunakan teknik non farmakologi seperti teknik relaksasi nafas dalam dengan cara menarik nafas dari hidung dan menghembuskan perlahan-lahan melalui mulut.

Menurut Lela (2018) teknik relaksasi dapat menurunkan nyeri dengan merilekskan ketegangan otot yang menunjang nyeri.Teknik relaksasi terdiri atas nafas abdomen dengan frekuensi lambat, berirama.Pemberian teknik relaksasi nafas dalam menciptakan kenyamanan, pasien merasa rileks dengan tindakan non farmakologi sehingga mampu meningkatkan suplai oksigen dalam sel tubuh yang akhirnya dapat mengurangi nyeri yang dialami klien (Purnawati, 2014).

Penelitian yang dilakukan oleh Winniarty (2016) dengan judul Pengaruh Terapi Ice Pack Terhadap Perubahan Skala Nyeri Pada Ibu Post Episiotomi juga mengatakan dalam penelitiannya bahwa penanganan nyeri dapat dilakukan secara farmakologis dan nonfarmakologis. Penanganan nyeri secara nonfarmakologis lebih aman diterapkan karena mempunyai risiko yang lebih kecil, tidak menimbulkan efek samping serta menggunakan proses fisiologis. Tingkat nyeri post episiotomi yang bervariasi terjadi karena insisi dan penjahitan pada saat episiotomi menimbulkan nyeri tajam dengan tingkat yang berbeda hal ini dikarenakan aktifnya nosiseptor perifer yang merupakan reseptor khusus penghantar stimulus noxious.

Penelitian yang dilakukan oleh Amita (2018) menyatakan terapi relaksasi nafas dalam dapat mengurangi intensitas nyeri pada pasien dengan dilakukan teknik relaksasi dapat menurunkan intensitas nyeri, saat dilakukan teknik relaksasi nafas dalam, pasien merelaksasikan otot-otot skelet yang mengalami spasme yang disebabkan oleh peningkatan prostaglandin sehingga terjadi vasodilatasi pembuluh darah dan akan meningkatkan aliran darah ke daerah yang mengalami spasme dan iskemik. Kemudian juga mampu merangsang tubuh untuk melepaskan opoiod endogen yaitu endorphin dan enkefalin, yang mana opoiod ini berfungsi sebagai (analgesik alami) untuk memblokir resptor 
pada sel-sel saraf sehingga mengganggu transmisi sinyal rasa sakit.

Selain itu tindakan keperawatan lain yang diberikan yaitu Menganjurkan kepada ibu agar perineum tetap bersih dan sesering mungkin mengganti pembalut. Menurut Herlina (2018) dalam penelitiannya mengatakan tujuan dilakukan perawatan perineum yaitu mencegah terjadinya infeksi sehubungan dengan penyembuhan jaringan.Infeksi menyebabkan peningkatan inflamasi dan nekrosis yang menghambat penyembuhan luka. Adanya benda asing, pengelupasan jaringan yang luas akan memperlambat penyembuhan dan kekuatan regangan luka menjadi tetap rendah. Karena perawatan yang kasar dan salah dapat mengakibatkan kapiler darah baru rusak dan mengalami perdarahan serta penyembuhan luka terhenti. Kemungkinan terjadinya infeksi pada luka karena perawatan yang tidak benar,dapat meningkat dengan adanya benda mati dan benda asing.

$$
\text { Evaluasi setelah dilakukan tindakan }
$$
keperawatan selama dua hari klien masalah teratasi. Hal ini sesuai dengan kriteria hasil yang telah dirumuskan yaitu perasaan nyaman dengan kondisi setelah melahirkan meningkat. Menurut Brunner \& Suddarth (2015) Evaluasi keperawatan adalah penilaian dengan cara membandingkan perubahan keadaan pasien (hasil yang diamati). Evaluasi adalah respon pasien terhadap terapi dan kemajuan mengarah pencapaian hasil yang diharapkan. Aktivitas berfungsi sebagai umpan balik dan bagian kontrol proses keperawatan, melalui mana status pernyataan diagnostik pasien secara individual dinilai untuk diselesaikan, dilanjutkan atau memerlukan perbaikan.

\section{KESIMPULAN}

Kesimpulan pada penelitian ini menunjukan bahwa perasaan nyaman yang berhubungan dengan kondisi setelah melahirkan meningkat.Saran Bagi RS Diharapkan dapat meningkatkan komunikasi dengan baik sehingga dapat memberikan pelayanan kesehatan yang lebih optimal kepada masyarakat. Bagi Responden Diharapakan ibu nifas dapat mempertahankan kebersihan perineum pada saat masa nifas sehingga penyembuhan luka perineum ibu dapat berjalan dengan normal dan merasakan kenyamanan pasca partum. Bagi Institusi Pendidikan Diharapkan penelitian ini dapat dijadikan sumber referensi, sumber bacaan dan bahan ajar terutama dalam internensi keperawatan pada pasien dengan ketidaknyamanan pasca partum. Bagi Peneliti SelanjutnyaDiharapkan penelitian selanjutnya dapat melakukan studi kasus ketidaknyamanan ibu pasca partum sectio.

\section{DAFTAR RUJUKAN}

Amita.D (2018).Pengaruh Teknik Relaksasi Nafas Dalam Terhadap Intensitas Nyeri Pada Pasien Post Operasi Sectio Caesarea Di Rumah Sakit Bengkulu.Jurnal Kesehatan Holistik (The Journal of Holistic Healthcare), Volume 12, No.1, Januari 2018: 26-28. Diakses 29 Mei 2020

Brunner \& Suddarth.(2015). Buku Ajar Keperawatan Medikan Bedah.Terjemahan Suzanne C.Smeltzer.edisi 9. Vol 9. Penerbit Buku Kedokteran EGC : Jakarta

Dewi Susilowati. (2018). Penggunaan Bebat Perineum (Kempitan) Untuk Mengurangi Nyeri Luka Perineum Pada Ibu Post Partum. Jurnal Terpadu Ilmu Kesehatan, Volume 7, No 1,Mei 2018, hlm 01 100.http://jurnalinterest.com.articel.diakses 20 Maret 2020 
Herlina.(2018). Hubungan Teknik Vulva Hygiene Dengan Penyembuhan Luka Perinium Pada Ibu Post Partum. Jurnal Kebidanan Vol 4, No 1, Januari 2018: 5-10. http://ejurnalmalahayati.ac.id/index.php/kebid anan/article/viewFile/636/570

Kementrian Kesehatan RI. (2018). Riset Kesehatan Dasar.Rikesdas 2018. Jakarta: Badan Penelitian Dan Pembangunan Kesehatan Kementrian Kesehatan RI.

Lela Aini..(2018). Pengaruh Teknik Relaksasi Nafas Dalam terhadap Penurunan Nyeri pada Pasien Fraktur. Jurnal KesehatanVolume 9, Nomor 2, Agustus 2018 ISSN 2086-7751 (Print), ISSN 2548-5695 (Online) http://ejurnal.poltekkestjk.ac.id/index.php/JK

Mutmainna Alka. (2017). Manajemen Asuhan Kebidanan Pada Ibu Post Partum.Jurnal Keperawatan Universitas Islam Negeri Alauddin.http://repositori.uinalauddin.ac.id/diakses 28 Maret 2020

Rekam Medik.(2020). RSD Liun Kendage Tahuna. Data Pasien Persalinan Normal dan Sectio Caesarea

Rosmiyati.(2016). Pengaruh terapi musik klasik terhadap nyeri jahitan perineum padaIbu nifas Teluk Betung Bandar Lampung.Jurnal Kebidanan. Vol 3, No 1, Januari 2017 : 50-56
Purnawati, Jolanda. (2014). Efektivitas Mobilisasi Dini pada Ibu Post Partum terhadap Percepatan Proses Penyembuhan Luka Sectio Caesarea Fase Inflamasi di RSUD Sanggau. Skripsi Mahasiswa Prodi Keperawatan, Fakultas Kedokteran Universitas Tanjungpura, Pontianak.

Setiadi, 2017, Konsep Dan Penulisan Riset Keperawatan, Graham Ilmu, Yogyakarta.

Sukmarani, S. (2018).Penerapan Pendidikan kesehatan Perawatan Luka Perineum Pada Ibu Postpartum dengan Pemenuhan Kebutuhan Belajar di PKM Godean. Jurnal Keperawatan.Eprints.ums.ac.id

Suryandari.G, (2019).Gambaran Asuhan Keperawatan Pada Ibu Post Partum Normal Dengan Ketidaknyamanan Pasca Partum di RSD Denpasar.Repository.Poltekes. Denpasar.ac.id

Weniarty (2016).Pengaruh Terapi Ice Pack Terhadap Perubahan Skala Nyeri Pada Ibu Post Episiotomi. JURNAL KEDOKTERAN DAN KESEHATAN, VOLUME 3, NO. 1, JANUARI 2016: 377-382. https://media.neliti.com/media/publications/18 1712-ID-pengaruh-terapi-ice-pack-terhadapperuba.pdf 